\title{
Unexpected rearrangements and a novel synthesis of 1,1-dichloro-1-alkenones from 1,1,1-trifluoroalkanones with aluminium trichloride
}

\author{
Beatrice Lansbergen, Catherine S. Meister and Michael C. McLeod
}

\section{Letter}

Address:

Bayer AG, Research \& Development Crop Science, Industriepark Höchst, 65926 Frankfurt, Germany

Email:

Michael C. McLeod ${ }^{*}$ - michael.mcleod@bayer.com

* Corresponding author

Keywords:

aluminium trichloride; dichloroalkenes; Friedel-Crafts alkylation;

rearrangement; trifluoroalkanes

\author{
Beilstein J. Org. Chem. 2021, 17, 404-409. \\ https://doi.org/10.3762/bjoc.17.36 \\ Received: 14 December 2020 \\ Accepted: 29 January 2021 \\ Published: 10 February 2021 \\ Associate Editor: K. Grela \\ (c) 2021 Lansbergen et al.; licensee Beilstein-Institut. \\ License and terms: see end of document.
}

\section{Abstract}

A novel reactivity of 1,1,1-trifluoroalkanones is reported, where the reaction with $\mathrm{AlCl}_{3}$ results in the formation of 1,1-dichloro-1alkenones. The reaction scope was found to be broad, with various chain lengths and aryl substituents tolerated. For substrates containing an electron-rich aromatic ring, further reactions take place, resulting in bicyclic and/or rearrangement products.

\section{Introduction}

1,1-Dichloro-1-alkenes are valuable synthetic intermediates and have been employed in Pd-mediated cross couplings of one or both chlorine atoms [1-7], carbonylation reactions [8], and $\mathrm{C}-\mathrm{H}$ bond alkynylations of heteroarenes [9]. The 1,1-dichloro-1alkenyl moiety is found in a number of pyrethroid insecticides including permethrin and marine natural products such as caracolamide A [10] (Figure 1).

1,1-Dichloro-1-alkenes $\mathbf{2}$ are commonly prepared from the corresponding aldehydes 1 in one step with $\mathrm{PPh}_{3}$ and $\mathrm{CHCl}_{3}$ [11], $\mathrm{CCl}_{4}$ [12], or with the phosphonate reagent $\mathrm{LiCCl}_{2}-\mathrm{P}(\mathrm{O})(\mathrm{OEt})_{2}$ $[13,14]$ (Figure 2a). Alternatively, the aldehydes are converted to trichloromethyl carbinols 3 using various methodologies [1517], followed by acetylation and elimination to provide the

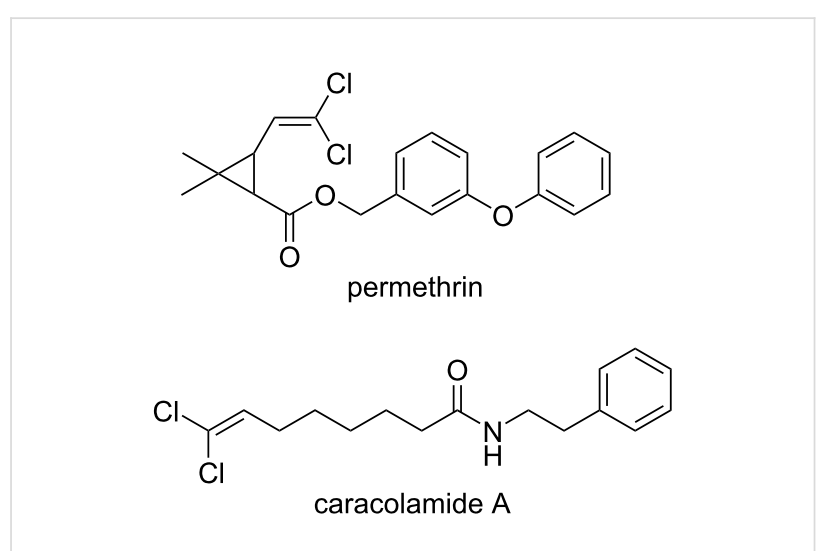

Figure 1: Examples of biologically active 1,1-dichloro-1-alkenes. 
desired dichloroalkenes [18-20]. The preparation of 1,1dichloro-1-alkenes from hydrazones [21] and from 2,2,2trichloroethyl carbonates [22] has also been reported. Internal difluoroalkanes have been used to generate chloroalkene products using $\mathrm{AlEt}_{2} \mathrm{Cl}[23,24]$. In this article we describe the $\mathrm{AlCl}_{3}$-mediated formation of 1,1-dichloro-1-alkenones $\mathbf{6}$ from 1,1,1-trifluoroalkanones $\mathbf{5}$, which in turn are accessed by the Grignard addition of 1,1,1-trifluoroalkylmagnesium halides to nitriles (Figure 2b). It is worth noting that the 1,1,1-trifluoroalkyl halides $(n=1,2,3)$ are commercially available, whereas the corresponding 1,1-dichloroalkenyl halides (or 1,1,1trichloroalkyl halides) are not. This methodology therefore represents a potentially useful access to the 1,1-dichloro-1alkenone moiety.

a)

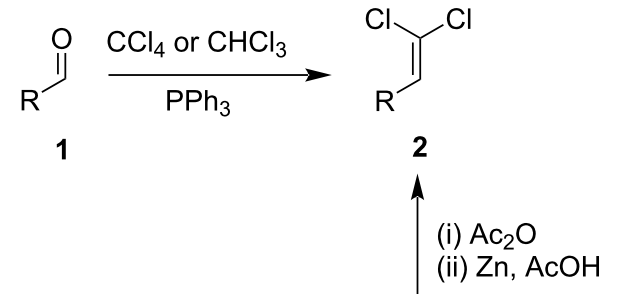

b)

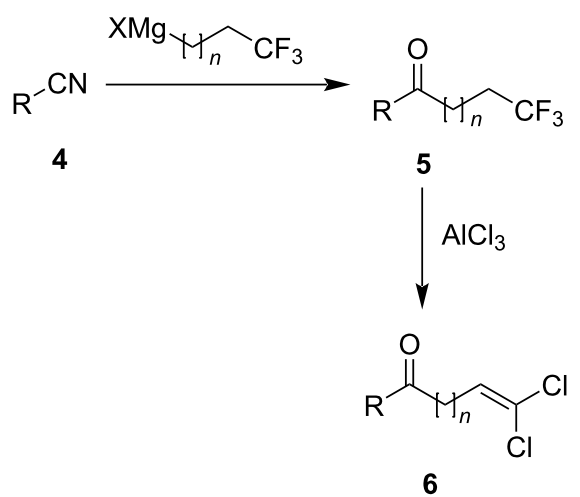

Figure 2: a) Common methods for the preparation of 1,1-dichloro-1alkenes from aldehydes. b) This work: a two-step synthesis of 1,1dichloro-1-alkenones from nitriles via 1,1,1-trifluoroalkanones.

\section{Findings}

Under initial conditions, $\mathrm{AlCl}_{3}$ was shown to invoke the conversion of 1,1,1-trifluoroalkanone 5a [25] to 1,1-dichloro-1alkenone $6 \mathbf{a}$ in $23 \%$ yield, without cleavage of the methyl ether [26] (Scheme 1). A similar $\mathrm{AlCl}_{3}$-promoted conversion of vinylic trifluoromethyl groups to 1,1-dichloroalkenes has previously been reported [27,28]. Additionally, 1,1-dichloroalkenes have also been prepared by the elimination of $\mathrm{HCl}$ from trichloroalkanes [29]. To the best of our knowledge, the direct conversion of an aliphatic $\mathrm{CF}_{3}$ group to a dichlorovinyl moiety has not been previously reported.

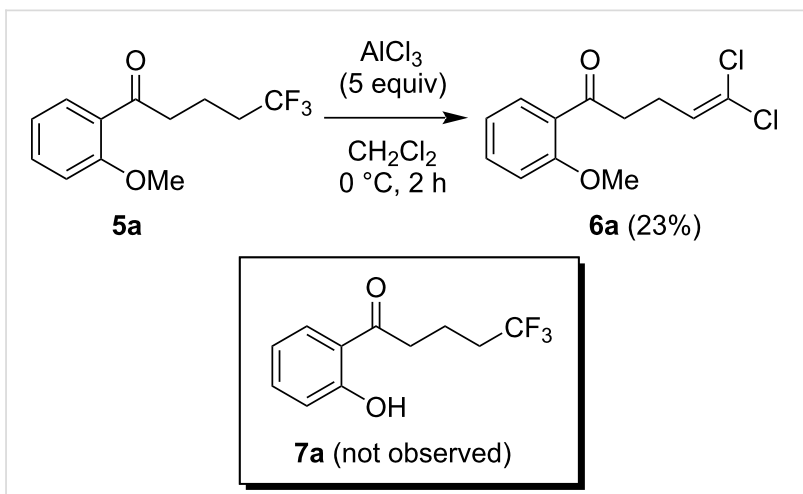

Scheme 1: The initial attempt for the conversion of 1,1,1-trifluoroalkanone 5 a to 1,1-dichloroalkenone $6 \mathbf{a}$.

Encouraged by these initial findings, we performed a screen of reaction conditions using the 3 -methoxy derivative $\mathbf{5 b}$ (Table 1). During this optimisation process, two things became quickly apparent: (1) the dichloroalkenones $\mathbf{6}$ are generally volatile and should be handled carefully (water bath $<30{ }^{\circ} \mathrm{C}$ ) and (2) under certain conditions, the trichloroalkanone $\mathbf{8 b}$ could also be isolated from the reactions. While the conversion of an aromatic trifluoromethyl to a trichloromethyl group with $\mathrm{AlCl}_{3}$ has been previously reported [30-32], investigations into the analogous transformation of aliphatic $\mathrm{CF}_{3}$ groups has been limited to adamantly-trifluoromethyl moieties [33,34].

An NMR analysis of the crude product mixture obtained using our original reaction conditions ( 5 equiv $\mathrm{AlCl}_{3}, \mathrm{CH}_{2} \mathrm{Cl}_{2}, 0{ }^{\circ} \mathrm{C}$ ) showed that, while dichloroalkenone $\mathbf{6 b}$ was the major product, a small amount of starting material $\mathbf{5 b}$ was still present along with significant quantities of the trichloroalkanone $\mathbf{8 b}$ (Table 1, entry 1). With a shorter reaction time of $1 \mathrm{~h}$, greater quantities of the trifluoroalkanone starting material $\mathbf{5 b}$ and trichloroalkanone $\mathbf{8 b}$ were observed (Table 1, entry 2), suggesting that compound $\mathbf{8 b}$ is an intermediate structure in the formation of dichloroalkenone $\mathbf{6 b}$. Attempts to reduce the number of equivalents of $\mathrm{AlCl}_{3}$ in the reaction were unsuccessful: only unreacted starting material was observed when 1 equivalent was employed, and 3 equivalents only gave low conversion (Table 1, entries 3 and 4). Replacing dichloromethane with 1,2-dichloroethane as solvent had a negligible effect on the reaction, however, all other solvents that were investigated failed to produce any desired dichloroalkenone product, with only unreacted $\mathbf{5 b}$ being observed in most cases (Table 1, entries 5-9). By increasing the temperature to $40{ }^{\circ} \mathrm{C}$, a full conversion of the starting material was observed, along with a decreased amount of the 
Table 1: Optimisation of the reaction conditions for the conversion of 1,1,1-trifluoroalkanone $5 \mathbf{b}$ to 1,1-dichloroalkenone $6 \mathbf{b}$.

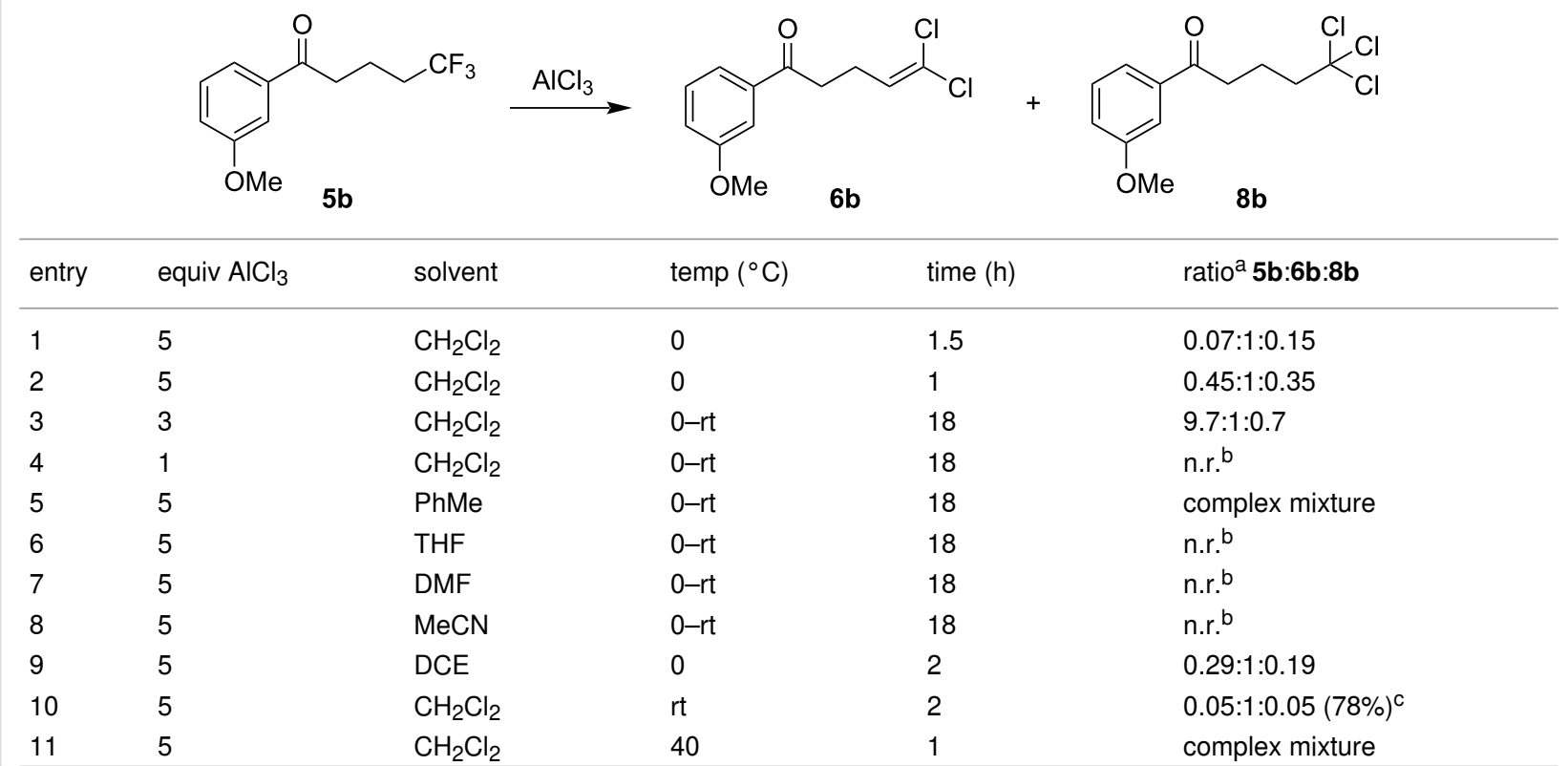

aDetermined by ${ }^{1} \mathrm{H}$ NMR analysis; ${ }^{b}$ n.r. = no reaction; ${ }^{C}$ isolated yield of $\mathbf{6 b}$.

trichloroalkanone $\mathbf{8 b}$, but at the expense of the formation of a number of other unidentified byproducts (Table 1, entry 11). At room temperature, the right balance of starting material conversion and minimisation of byproduct formation was reached, so that dichloroalkenone $\mathbf{6 b}$ could be isolated in $78 \%$ yield (Table 1, entry 10).
With an optimised set of conditions established for this reaction, we turned our attention to investigating the substrate scope (Scheme 2). The required trifluoroalkanone starting materials were prepared in one step from the corresponding benzonitrile by reaction with the required trifluoroalkylmagnesium iodide (see Supporting Information File 1).<smiles>COc1cccc(C(=O)CCC=C(Cl)Cl)c1</smiles> 
The substrate scope of the reaction proved quite broad; all phenyl-containing substrates $\mathbf{5 a}-\mathbf{g}$ could be transformed into the desired products $\mathbf{6 a}-\mathbf{g}$. Using these optimised conditions, the isolated yield of our original dichloroalkene 6a (Scheme 1) could be increased from $23 \%$ to $78 \%$. Naphthalene $\mathbf{6 h}$ and 2-pyridine 6i were also successfully obtained, however, the reactions with the 3 - and 4-pyridines $\mathbf{5} \mathbf{j}$ and $\mathbf{5 k}$ resulted in complex mixtures from which no desired product, nor starting material, could be observed. The scope of this chemistry also extends to substrates with a shorter trifluoroalkanone chain, allowing the preparation of 1,1-dichlorobutenone $\mathbf{6}$ and 1,1dichloropropenone $\mathbf{6 m}$, although the latter compound required a considerably longer reaction time (5 days). For some of the above reactions, the crude product obtained after work-up was sufficiently clean ( $>90 \%$ purity as determined by ${ }^{1} \mathrm{H}$ NMR) that no further purification was necessary. The other products needed to be purified by either normal and/or reversed-phase chromatography, resulting in significantly lower yields, in part due to the volatile nature of the products.

The longer reaction time of trifluoropentanone derivative $\mathbf{5 m}$ compared to the longer chain substrates (e.g., 5c and $\mathbf{5 l}$ ) could be explained mechanistically by the formation of a terminal carbocation upon the extraction of a fluorine atom by the aluminium species (Scheme 3). This carbocation could be stabilised to varying degrees by the ketone moiety, depending on the alkyl chain length. For longer chains where $n=1$ or 2 , this stabilisation would occur via a favoured 5- or 6-ring intermediate, respectively, while for shorter chains $(n=0)$, an unfavoured 4-membered ring would be required.

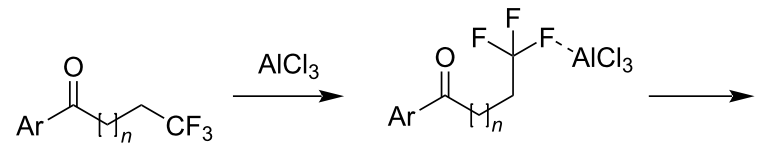

5

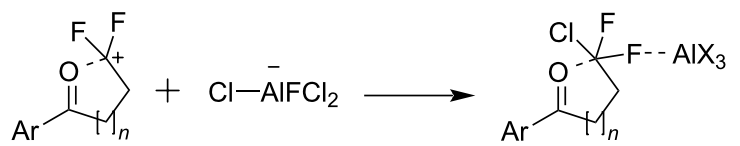<smiles>C#CCCCCCCCCCC(=O)NCC(Cl)(Cl)Cl</smiles>

8

6

Scheme 3: Proposed mechanism for the formation of dichloroalkene 6 from trifluoroalkanone 5

When the 3-methoxy derivative $\mathbf{5 b}$ was treated with 7 (instead of 5) equivalents of $\mathrm{AlCl}_{3}$, a further two products were ob- tained, whose structures were elucidated as the 8,9-dihydrobenzo[7]annulen-9-ones 9 and $\mathbf{1 0}$ (Scheme 4). Presumably, these bicyclic compounds arise via an intramolecular Friedel-Crafts alkylation of $\mathbf{6 b}$, promoted by the ortho/paradirecting nature of the methoxy substituent, and a subsequent elimination of $\mathrm{HCl}$. No such transformation was observed with the other trifluoroalkanone substrates, including the 2- and 4-methoxy substrates 5a and $\mathbf{5 f}$, presumably as only the metamethoxy group is able to sufficiently activate the two positions adjacent to the ketone.

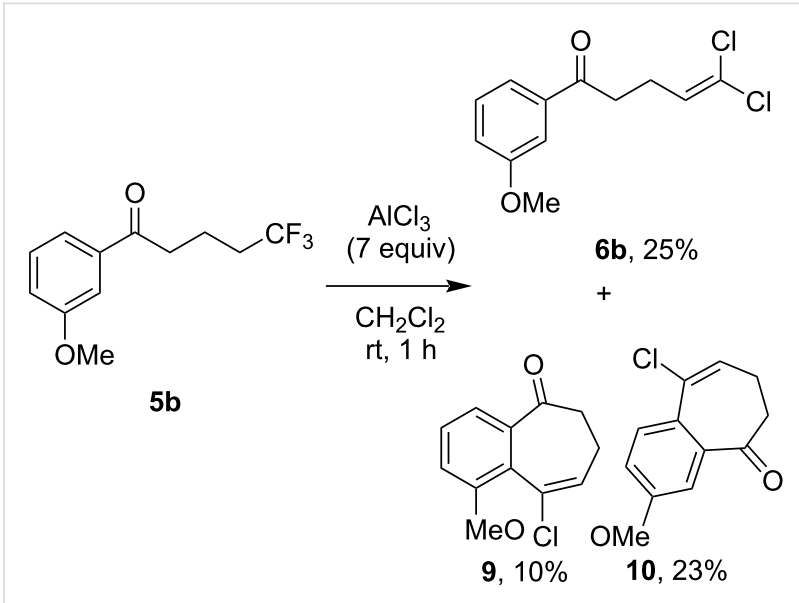

Scheme 4: Formation of bicyclic ketones 9 and 10 from 1,1,1-trifluoroalkanone $5 \mathrm{~b}$ using 7 equivalents of $\mathrm{AICl}_{3}$.

When the 4-methoxy derivative $5 n$ was treated with $\mathrm{AlCl}_{3}$ using our standard conditions, none of the expected 1,1dichloroalkenone $\mathbf{6 n}$ was obtained. Instead, the acid chloride $\mathbf{1 3}$ was isolated in an excellent yield (Scheme 5). The structure of this product was elucidated using 2D-NMR experiments, with an HMBC cross-peak between the aryl ring and the alkene moiety proving most illuminating (see Supporting Information File 1). The geometry of the double bond was determined from a NOE interaction between the alkene proton and the ring hydrogen atoms. This molecule could not however be detected by mass spectrometry and so it was converted to carboxylic acids 14 and 15 by the treatment with silica gel and $\mathrm{NaOH}$, respectively, in order to confirm its identity. A possible mechanism for the formation of $\mathbf{1 3}$ from $\mathbf{5 n}$ could involve the formation of a terminal carbocation from trichloroalkanone $\mathbf{8 n}$, followed by a favoured 6-endo-trig cyclisation driven by the 4-methoxy group to form the 6,6-spirocycle 11. The addition of water and subsequent ring-opening would then form the acid 12, which upon elimination of water would then provide the observed acid chloride $\mathbf{1 3}$.

We wished to also determine whether the described reactivity would be observed with substrates not containing a ketone 


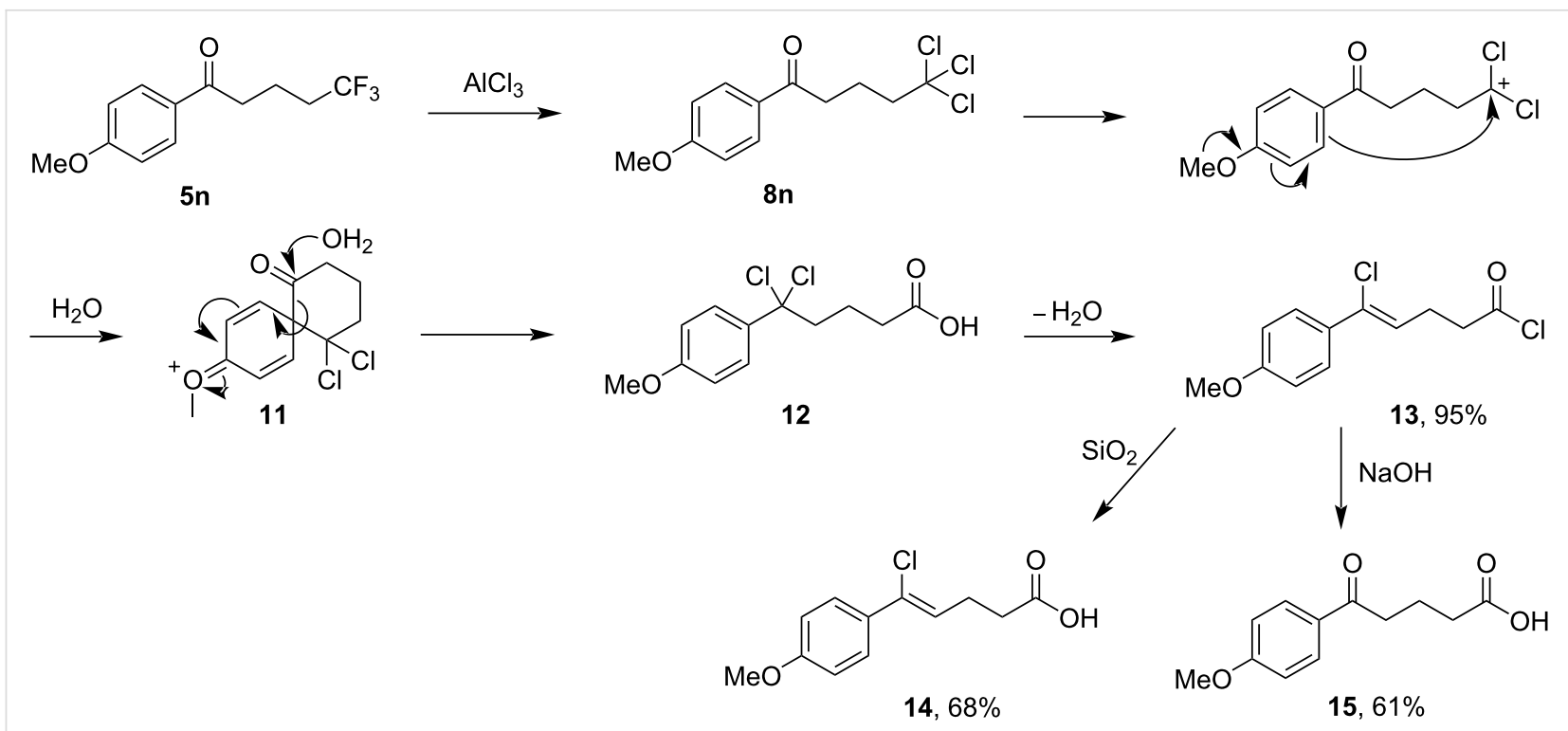

Scheme 5: Conversion of 1,1,1-trifluoroalkanone $5 \mathrm{n}$ to acid chloride 13 with $\mathrm{AlCl}_{3}$, and possible mechanism.

linker. Replacing the ketone moiety with an oxygen or sulphur atom proved unsuccessful, with only complex mixtures being obtained the upon treatment with $\mathrm{AlCl}_{3}$ (see Supporting Information File 1). This observation suggests that the role of the ketone moiety is not only to stabilise the putative carbocation as discussed earlier, but also to deactivate the aromatic ring to Friedel-Craft-type alkylations.

However, when the trifluoropentylbenzene $\mathbf{1 6}$ was prepared and subjected to the standard $\mathrm{AlCl}_{3}$ conditions (Scheme 6), a single product was isolated from the reaction that, after careful elucidation (see Supporting Information File 1), was identified as the bicycle 17. This compound could potentially arise via an initial conversion to the dichloroalkyl cation $\mathbf{1 8}$, followed by a ring closure and elimination of $\mathrm{HCl}$ to form the 6,6-spirocycle 19. A 1,2-rearrangement would then produce the observed product 17. Presumably the analogous dichloroalkenone 6d does not undergo this cyclisation due to the deactivation of the ring by the ketone towards nucleophilic attack.

\section{Conclusion}

In conclusion, we have shown that 1,1,1-trifluoroalkanones can be converted into 1,1-dichloro-1-alkenes when treated with $\mathrm{AlCl}_{3}$, allowing for an alternate and rapid route to this soughtafter moiety. With 3- and 4-methoxy-substituted substrates, the initially formed dichloroalkene products are sufficiently electron rich to allow further reactions, giving rise to [6,7]bicyclic ketones $\mathbf{9}$, and $\mathbf{1 0}$ and the linear acid chloride $\mathbf{1 3}$, respectively. We have also found that when the ketone is not present, the trifluoroalkyl substrate is converted into bicyclic vinyl chloride $\mathbf{1 7}$ when treated with $\mathrm{AlCl}_{3}$. We hope that this short communica-

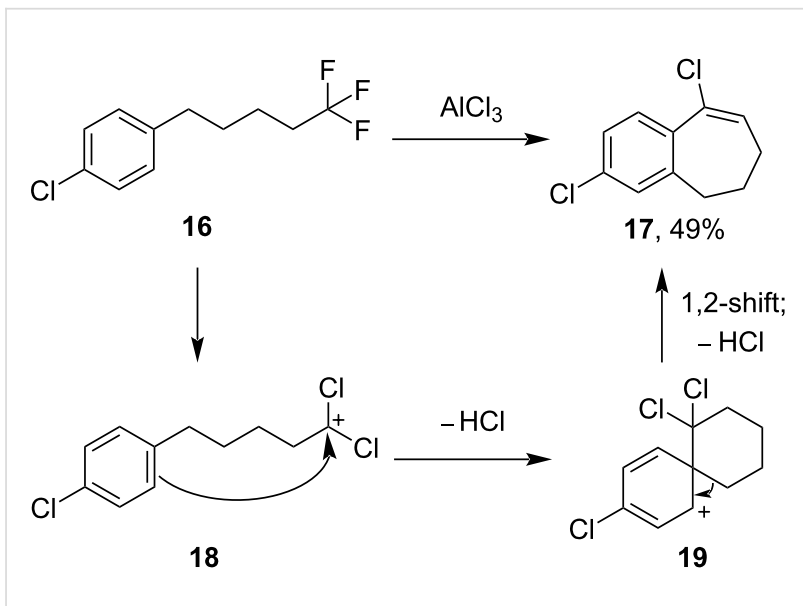

Scheme 6: Conversion of 1,1,1-trifluoroalkane 16 to bicycle 17 upon treatment with $\mathrm{AICl}_{3}$, and possible mechanism.

tion will inspire other researchers to utilise this functional group conversion in future syntheses of 1,1-dichloro-1-alkenes and to further investigate the unexpected reactivity of these compounds.

\section{Supporting Information}

\section{Supporting Information File 1}

Detailed experimental procedures and NMR spectra for all compounds referenced.

[https://www.beilstein-journals.org/bjoc/content/ supplementary/1860-5397-17-36-S1.pdf] 


\section{Acknowledgements}

We thank Mr Martin Annau for his valuable assistance in NMR interpretation and structure elucidation, Mrs Susanne Ries for performing the mass spectrometry measurements and Dr Samuel J. Davidson for careful proof-reading of the manuscript and helpful discussions.

\section{ORCID ${ }^{\circledR}$ iDs}

Catherine S. Meister - https://orcid.org/0000-0002-1983-2056 Michael C. McLeod - https://orcid.org/0000-0002-0246-1666

\section{References}

1. Minato, A.; Suzuki, K.; Tamao, K. J. Am. Chem. Soc. 1987, 109, 1257-1258. doi:10.1021/ja00238a052

2. Minato, A. J. Org. Chem. 1991, 56, 4052-4056. doi:10.1021/jo00012a048

3. Shi, J.-c.; Negishi, E.-i. J. Organomet. Chem. 2003, 687, 518-524. doi:10.1016/j.jorganchem.2003.09.008

4. Shi, J.-c.; Zeng, X.; Negishi, E.-i. Org. Lett. 2003, 5, 1825-1828. doi:10.1021/ol030017x

5. Tan, Z.; Negishi, E.-i. Angew. Chem., Int. Ed. 2006, 45, 762-765. doi:10.1002/anie.200503519

6. Andrei, D.; Wnuk, S. F. J. Org. Chem. 2006, 71, 405-408. doi:10.1021/jo051980e

7. Liron, F.; Fosse, C.; Pernolet, A.; Roulland, E. J. Org. Chem. 2007, 72, 2220-2223. doi:10.1021/j0061908w

8. Arthuis, M.; Lecup, A.; Roulland, E. Chem. Commun. 2010, 46, 7810-7812. doi:10.1039/c0cc02517h

9. Ackermann, L.; Kornhaass, C.; Zhu, Y. Org. Lett. 2012, 14, 1824-1826. doi:10.1021/ol300514d

10. Naman, C. B.; Almaliti, J.; Armstrong, L.; Caro-Díaz, E. J.; Pierce, M. L.; Glukhov, E.; Fenner, A.; Spadafora, C.; Debonsi, H. M.; Dorrestein, P. C.; Murray, T. F.; Gerwick, W. H. J. Nat. Prod. 2017, 80, 2328-2334. doi:10.1021/acs.jnatprod.7b00367

11. Speziale, A. J.; Ratts, K. W. J. Am. Chem. Soc. 1962, 84, 854-859. doi:10.1021/ja00864a035

12. Rabinowitz, R.; Marcus, R. J. Am. Chem. Soc. 1962, 84, 1312-1313. doi:10.1021/ja00866a056

13. Seyferth, D.; Marmor, R. S. J. Organomet. Chem. 1973, 59, 237-245. doi:10.1016/s0022-328x(00)95040-x

14. Villieras, J.; Perriot, P.; Normant, J. F. Synthesis 1975, 458-461. doi:10.1055/s-1975-23805

15. Tanaka, H.; Yamashita, S.; Yamanoue, M.; Torii, S. J. Org. Chem. 1989, 54, 444-450. doi:10.1021/jo00263a035

16. Corey, E. J.; Link, J. O.; Shao, Y. Tetrahedron Lett. 1992, 33, 3435-3438. doi:10.1016/s0040-4039(00)92656-x

17. Aggarwal, V. K.; Mereu, A. J. Org. Chem. 2000, 65, 7211-7212. doi:10.1021/j0000584n

18. Kryshtal, G. V.; Bogdanov, V. S.; Yanovskaya, L. A.; Volkov, Yu. P.; Trusova, E. I. Tetrahedron Lett. 1982, 23, 3607-3610. doi:10.1016/s0040-4039(00)87684-4

19. Zhdankina, G. M.; Kryshtal', G. V.; Serebreyakov, É. P.; Yanovaskaya, L. A.

Bull. Acad. Sci. USSR, Div. Chem. Sci. (Engl. Transl.) 1988, 37, 2589-2591. doi:10.1007/bf00952654
20. Wang, Z.; Campagna, S.; Xu, G.; Pierce, M. E.; Fortunak, J. M.; Confalone, P. N. Tetrahedron Lett. 2000, 41, 4007-4009. doi:10.1016/s0040-4039(00)00547-5

21. Shastin, A. V.; Korotchenko, V. N.; Nenajdenko, V. G.; Balenkova, E. S. Tetrahedron 2000, 56, 6557-6563. doi:10.1016/s0040-4020(00)00606-2

22. Ram, R. N.; Tittal, R. K. Tetrahedron Lett. 2014, 55, 4342-4345. doi:10.1016/j.tetlet.2014.05.097

23. Wang, J.; Ogawa, Y.; Shibata, N. iScience 2019, 17, 132-143. doi:10.1016/j.isci.2019.06.018

24. Wang, J.; Ogawa, Y.; Shibata, N. Sci. Rep. 2019, 9, 19113. doi:10.1038/s41598-019-55206-7

25. Deprez, N. R.; Reddy, R. P.; Sharpe, P. L.; Stevenson, T. M. Pyrimidinyloxy benzene derivatives as herbicides. WO Pat. Appl. WO2015/108779 A1, July 23, 2015.

26. Kawamura, Y.; Takatsuki, H.; Torii, F.; Horie, T. Bull. Chem. Soc. Jpn. 1994, 67, 511-515. doi:10.1246/bcsj.67.511

27. Van Der Puy, M. J. Org. Chem. 1997, 62, 6466-6468. doi:10.1021/j0970655r

28. Liu, Z.; Tu, X.-S.; Guo, L.-T.; Wang, X.-C. Chem. Sci. 2020, 11, 11548-11553. doi:10.1039/d0sc03883k

29. Fontana, G.; Frenna, V.; Lamartina, L.; Natoli, M. C.; Noto, R. J. Phys. Org. Chem. 2002, 15, 108-114. doi:10.1002/poc.459

30. Henne, A. L.; Newman, M. S. J. Am. Chem. Soc. 1938, 60, 1697-1698. doi:10.1021/ja01274a046

31. Riera, J.; Castañer, J.; Carilla, J.; Robert, A. Tetrahedron Lett. 1989, 30, 3825-3828. doi:10.1016/s0040-4039(01)80668-7

32. Goh, K. K. K.; Sinha, A.; Fraser, C.; Young, R. D. RSC Adv. 2016, 6, 42708-42712. doi:10.1039/c6ra09429e

33. Sorochinskii, A. E.; Aleksandrov, A. M.; Kukhar, V. P. Zh. Org. Khim. 1979, 15, 1555-1556.

34. Duddeck, H.; Spitzer, M.; Bolte, G. Liebigs Ann. Chem. 1985, 545-554. doi:10.1002/jlac.198519850315

\section{License and Terms}

This is an Open Access article under the terms of the

Creative Commons Attribution License

(https://creativecommons.org/licenses/by/4.0). Please note that the reuse, redistribution and reproduction in particular requires that the author(s) and source are credited and that individual graphics may be subject to special legal provisions.

The license is subject to the Beilstein Journal of Organic Chemistry terms and conditions:

(https://www.beilstein-journals.org/bjoc/terms)

The definitive version of this article is the electronic one which can be found at:

https://doi.org/10.3762/bjoc.17.36 